\title{
Discriminatory Effectiveness of Crown Indexes-Tests Between American Blacks and Whites
}

\author{
Candice L. Foster and Edward F. Harris* \\ College of Dentistry, University of Tennessee, Memphis, TN 38163
}

\begin{abstract}
Tooth crown shapes differ among human groups because the sizes and shapes of the constituent crown components differ. It was of interest to us whether there is patterned variation in crown indexes between sexes or among ethnic groups. The crown index-buccolingual width as a function of mesiodistal length-was analyzed here in terms of sex and race differences in a cohort of American black and white adolescents $(n=324)$ from the U.S. Mid-South. The mandibular canine is distinctive in exhibiting significant sexual dimorphism in crown shape, with females being broader in terms of mesiodistal length. Prior literature reports the crown indexes of several tooth types to be dimorphic, which does not occur here, showing that the
\end{abstract}

Crowns of teeth vary both in size and shape, and this is well documented by dental anthropologists who have detailed the variations in the morphologies of all tooth types (e.g., Korenhof, 1960; Morris, 1965; Turner et al. 1991; Scott, 2008). In turn, differences in the number and size of cusps, cingular features, and other details of the crown influence tooth size (e.g., Kondo and Townsend, 2006). Conversely, tooth size is statistically and developmentally associated with crown complexity (e.g., Keene, 1968; Garn 1977).

Researchers have traditionally focused on the maximum mesiodistal (MD) and buccolingual (BL) diameters of teeth (Goose, 1963), though other dimensions may be at least as informative (Corruccini, 1979; Hillson et al., 2005). Aside from some Australian and Melanesian groups with very large tooth sizes, there are rather few obvious intergroup differences in crown dimensions, and this has dampened anthropologists' enthusiasm for collecting tooth size data (e.g., Lasker and Lee, 1957; Moorrees, 1957). The disinterest in odontometrics has been compounded by the slow growth of analytic methods that are tractable and actually address anthropological questions (see, e.g., Reyment et al., 1984; Hanihara and Ishida, 2005). One early thought was that, if tooth crown sizes don't vary much across populations, perhaps tooth shape would be informative (e.g., Hrdlička, 1923; Nelson, 1938; Selmer-Olsen, 1949). Calculating shape indexes also extends logically from the numerous ratios calculated by anthropometrists, extent of sexual dimorphism differs among groups. In contrast, we found that multiple crown indexes differ significantly between the samples of blacks and whites, with the largest differences in UC, UP1, and LM2. Of note, nature of the differences are tooth-specific, suggesting that divergence among groups at this microevolutionary level has shifted crown shapes along distinctive (rather than parallel) pathways. The optimum subset of crown indexes correctly allocates $67 \%$ of the specimens as to race; this percentage is not much better than chance, suggesting that crown indexes are of little forensic usefulness in discriminating among contemporary humans. Dental Anthropology 2009;22(3):85-92.

osteologists, and craniometrists that emphasize shape rather than size differences (e.g., Wilder, 1920; Martin, 1928), though Albrecht et al. (1993) provide some cautionary notes against the uncritical use of ratios.

The crown index (BL/MD times 100) has long been used as a measure of crown shape. Selma Thomsen (1955, p 4) states that, "This index was introduced by Retzius, a Swedish anatomist," but she does not supply a citation. Anders Retzius (b.1796-d.1860) is better known in dental circles as the person who described histological features of the enamel: "In ground section the enamel is marked by brown bands called the bands, striae, or incremental lines of Retzius" (Bhaskar, 1962, p 103). Application of the crown index evidently caught on quickly; de Terra reports it (Zahnbogenindex) without explanation (de Terra, 1905). The crown index expresses crown width (BL) as a function of length (MD), so a large index reflects a broad-short crown form, while a small index indicates a narrow-long form. The index is only an approximate measure of shape because tooth crowns are not essentially rectangular in form.

The purpose of the present study is to explore the utility of using crown indexes of the permanent teeth to distinguish between males and females and, secondly,

Correspondence to: Edward F. Harris, Department of Orthodontics, University of Tennessee, Memphis, TN 38163.

E-mail: eharris@utmem.edu 
to test for differences between American blacks and whites. These differences may suggest intra-specific ('racial') differences in modal crown development. So too, the data may be of forensic use in estimating the race and/or sex of an unknown specimen (e.g., Ditch and Rose, 1972).

\section{MATERIALS AND METHODS}

The crown dimensions measured from full-mouth dental cases were obtained from 324 adolescents in whom all 28 permanent teeth (omitting third molars) were fully erupted. Teeth were intact (not affected by caries, trauma, or casting defects). Teeth from just one side of the arch were measured because of the essential symmetry of the dentition. Electronic-readout sliding calipers were used (precise to $0.005 \mathrm{~mm}$ ), with beaks machined to fit well into the embrasures, and the measurement method described by Seipel (1946) was followed.

Subjects had been patients in the Department of Orthodontics at the College of Dentistry, Memphis, Tennessee, and sample sizes were 52 black males, 74 black females, 94 white males, and 104 white females. Cases were phenotypically normal, and cases with congenitally absent teeth (ignoring third molars) were not included (Garn and Lewis, 1970; Kirveskari et al., 1978).

The crown index of each of the 14 tooth types was calculated using a spreadsheet program, and two-way factorial analysis of variance (Winer et al., 1991) was used to concurrently test for race and sex differences. Stepwise discriminant functions analysis (Cooley and Lohnes, 1971) then was used to find optimal subsets of the variables that maximally separate the sexes (or the races). Statistics were performed using JMP (SAS Institute, Cary, NC) and SPSS (SPSS Inc., Chicago, IL).

\section{RESULTS}

\section{Univariate analysis}

Descriptive statistics are listed in Table 1, where it is evident that the majority of mean crown indexes are above 100 simply because BL breadths exceed MD lengths (Keith, 1916). The maxillary premolars have the highest indexes, on the order of 130 for P1 and 140 for P2. At the other end of the spectrum, maxillary incisors (I1, I2) have means appreciably below 100 because their crowns are wide but narrow faciolingually. The lower molars also have small mean indexes, at about 94 (M1) and 97 (M2), probably because the talonid, which extends crown length mesiodistally, is well developed on these teeth.

Statistical tests for sex differences (Table 2) are interesting because only one of the 14 F-ratios achieved significance $(\mathrm{P}<0.05)$, but, of note, the significant sexual dimorphism (for the lower canine) is highly significant $(\mathrm{P}<0.0001)$. In other words, while males tend to have larger crown dimensions than females (e.g., Garn et al., 1967; Potter, 1972), the length-to-width ratios tend to be the same in the two sexes for most tooth types. The exception is that the crown index for LC is appreciably higher in females than males (Fig. 1), and inspection of the sizes shows that the sex difference is principally due to the much greater MD length of LC in males (whereas the BL sex difference is trivial). This strong statistical difference suggests that LC crown shape may be useful for sex discrimination.

Half of the crown indexes $(7 / 14)$ are significantly different between the black and white samples (Table

TABLE 1. Descriptive statistics for the crown index, by race and sex

\begin{tabular}{rrrrrrrrr}
\hline Tooth & \multicolumn{2}{c}{ Black Females } & \multicolumn{2}{c}{ Black Males } & \multicolumn{2}{c}{ White Females } & \multicolumn{2}{c}{ White Males } \\
Type & $\overline{\mathrm{x}}$ & $\mathrm{sd}$ & $\overline{\mathrm{x}}$ & $\mathrm{sd}$ & $\overline{\mathrm{x}}$ & $\mathrm{sd}$ & $\overline{\mathrm{x}}$ & $\mathrm{sd}$ \\
\hline & & & \multicolumn{2}{c}{ Maxilla } \\
I1 & 81.92 & 6.42 & 81.07 & 6.78 & 81.37 & 8.76 & 80.55 & 7.07 \\
$\mathrm{I} 2$ & 93.75 & 8.94 & 93.19 & 9.79 & 90.75 & 10.68 & 91.31 & 11.90 \\
$\mathrm{C}$ & 106.35 & 7.18 & 104.12 & 6.81 & 102.44 & 9.08 & 102.93 & 8.77 \\
P1 & 130.51 & 5.75 & 129.52 & 6.85 & 132.61 & 7.41 & 133.35 & 8.01 \\
P2 & 141.00 & 8.54 & 142.68 & 8.20 & 139.84 & 8.52 & 141.66 & 9.36 \\
M1 & 109.50 & 5.72 & 109.39 & 6.17 & 110.58 & 5.26 & 111.26 & 5.56 \\
M2 & 107.82 & 6.80 & 107.53 & 6.50 & 109.51 & 8.94 & 108.33 & 6.33 \\
& & & & Mandible & & & & \\
I1 & 105.97 & 8.20 & 103.42 & 9.60 & 105.65 & 9.53 & 107.01 & 9.52 \\
I2 & 102.87 & 7.20 & 101.52 & 9.64 & 100.89 & 8.51 & 99.38 & 9.37 \\
C & 104.37 & 6.63 & 99.83 & 9.27 & 104.17 & 9.15 & 100.21 & 10.00 \\
P1 & 108.94 & 6.51 & 109.26 & 8.23 & 109.65 & 7.73 & 110.48 & 7.05 \\
P2 & 118.40 & 8.25 & 120.30 & 9.07 & 117.70 & 7.94 & 118.72 & 8.16 \\
M1 & 93.52 & 4.71 & 92.29 & 4.38 & 94.09 & 4.70 & 94.26 & 5.02 \\
M2 & 95.90 & 6.48 & 93.03 & 6.19 & 97.05 & 5.87 & 98.60 & 5.89 \\
\hline
\end{tabular}




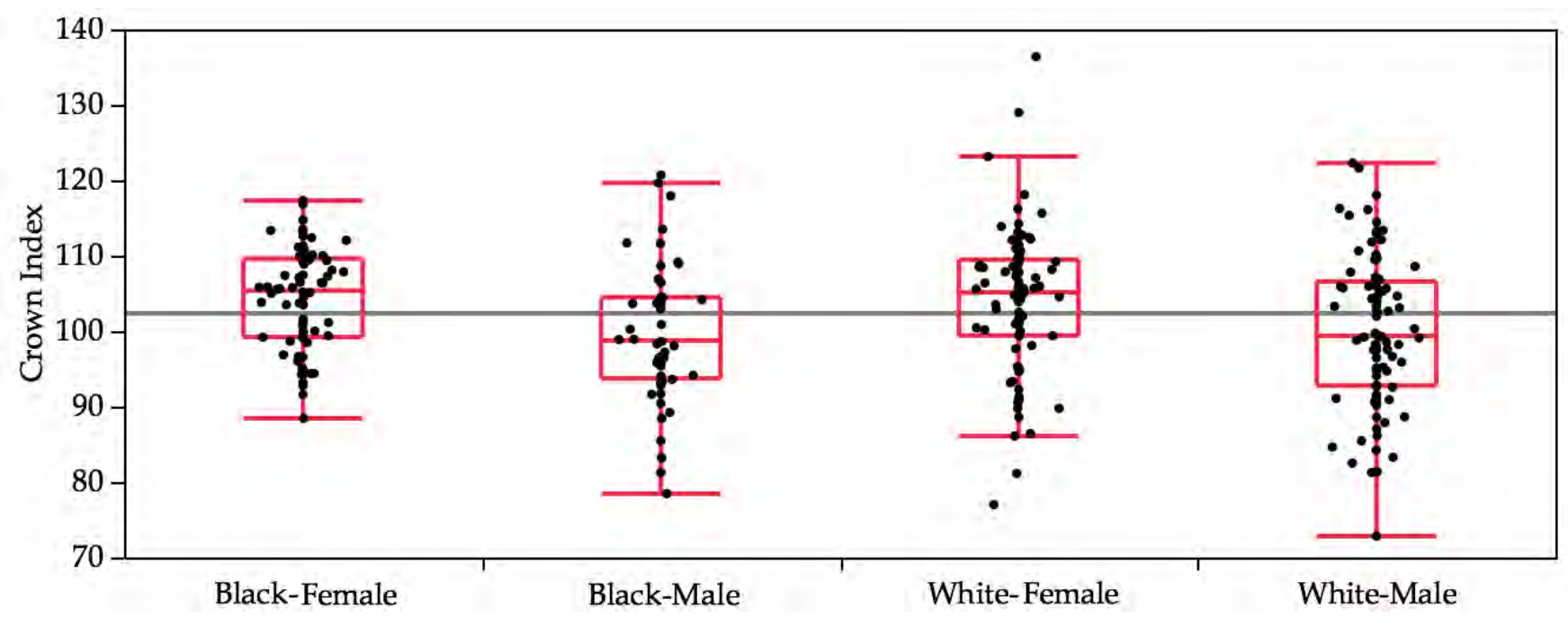

Fig. 1. Boxplots showing the distributions of the crown index for mandibular canine. Median indexes are higher in females than males in both the black and white samples.

2) when assessed univariately (alpha $=0.05)$. There is, however, a complexity as to which group has the larger crown index (Fig. 2). Inspecting the F-ratios, two teeth stand out as particularly different, namely maxillary P1 and mandibular M2. In both comparisons, the white sample has the larger crown index, indicating that these teeth are more broad-and-short in whites than blacks.

\section{Multivariate analysis}

We used stepwise discriminant functions analysis to identify the subsets of variables that are most predictive of sex and, separately, most predictive of race. Prior probabilities were set to be equal across groups.
As suggested by the univariate analysis (Table 2), only the crown index of LC is predictive of a subject's sex. When all 14 indexes are input into the discriminant algorithm (races combined), just LC is retained, and it correctly classified $62 \%$ of the cases as to sex using the jackknife ("leave-one-out") method. This percentage is better than chance, but is not as reliable as other skeletal and dental methods (e.g., Buikstra and Ubelaker, 1994).

Using the 14 indexes to estimate race (either American black or white), the stepwise procedure retained 5 of the 14 variables (sexes combined). This is a fairly large number of variables, and it suggests that the crown indexes are not strongly intercorrelated (Garn et al., 1967c). Correct allocation is $67 \%$ (jackknife)

TABLE 2. Results of factorial ANOVA tests for race and/or sex differences in crown indexes

\begin{tabular}{|c|c|c|c|c|c|c|}
\hline \multirow{2}{*}{$\begin{array}{l}\text { Tooth } \\
\text { Type }\end{array}$} & \multicolumn{2}{|c|}{ Race } & \multicolumn{2}{|c|}{ Sex } & \multicolumn{2}{|c|}{ Interaction } \\
\hline & F Ratio & $\overline{P \text { Value }}$ & F Ratio & P Value & F Ratio & P Value \\
\hline & & & Maxilla & & & \\
\hline I1 & 0.38 & 0.5404 & 0.93 & 0.3348 & 0.00 & 0.9857 \\
\hline I2 & 3.99 & 0.0466 & 0.00 & 0.9966 & 0.21 & 0.6448 \\
\hline C & 7.22 & 0.0076 & 0.84 & 0.3589 & 2.05 & 0.1532 \\
\hline P1 & 12.79 & 0.0004 & 0.02 & 0.8825 & 1.09 & 0.2963 \\
\hline P2 & 1.17 & 0.2794 & 3.03 & 0.0826 & 0.00 & 0.9458 \\
\hline M1 & 5.20 & 0.0232 & 0.20 & 0.6572 & 0.39 & 0.5345 \\
\hline M2 & 2.14 & 0.1441 & 0.75 & 0.3876 & 0.27 & 0.6059 \\
\hline & & & Mandible & & & \\
\hline I1 & 2.34 & 0.1272 & 0.31 & 0.5756 & 3.35 & 0.0680 \\
\hline I2 & 4.22 & 0.0409 & 2.04 & 0.1546 & 0.01 & 0.9372 \\
\hline C & 0.01 & 0.9317 & 17.07 & $<0.0001$ & 0.08 & 0.7803 \\
\hline P1 & 1.26 & 0.2629 & 0.44 & 0.5093 & 0.09 & 0.7684 \\
\hline P2 & 1.43 & 0.2331 & 2.33 & 0.1282 & 0.21 & 0.6465 \\
\hline M1 & 5.35 & 0.0213 & 0.93 & 0.3352 & 1.62 & 0.2041 \\
\hline M2 & 17.21 & $<0.0001$ & 0.67 & 0.4152 & 7.47 & 0.0067 \\
\hline
\end{tabular}




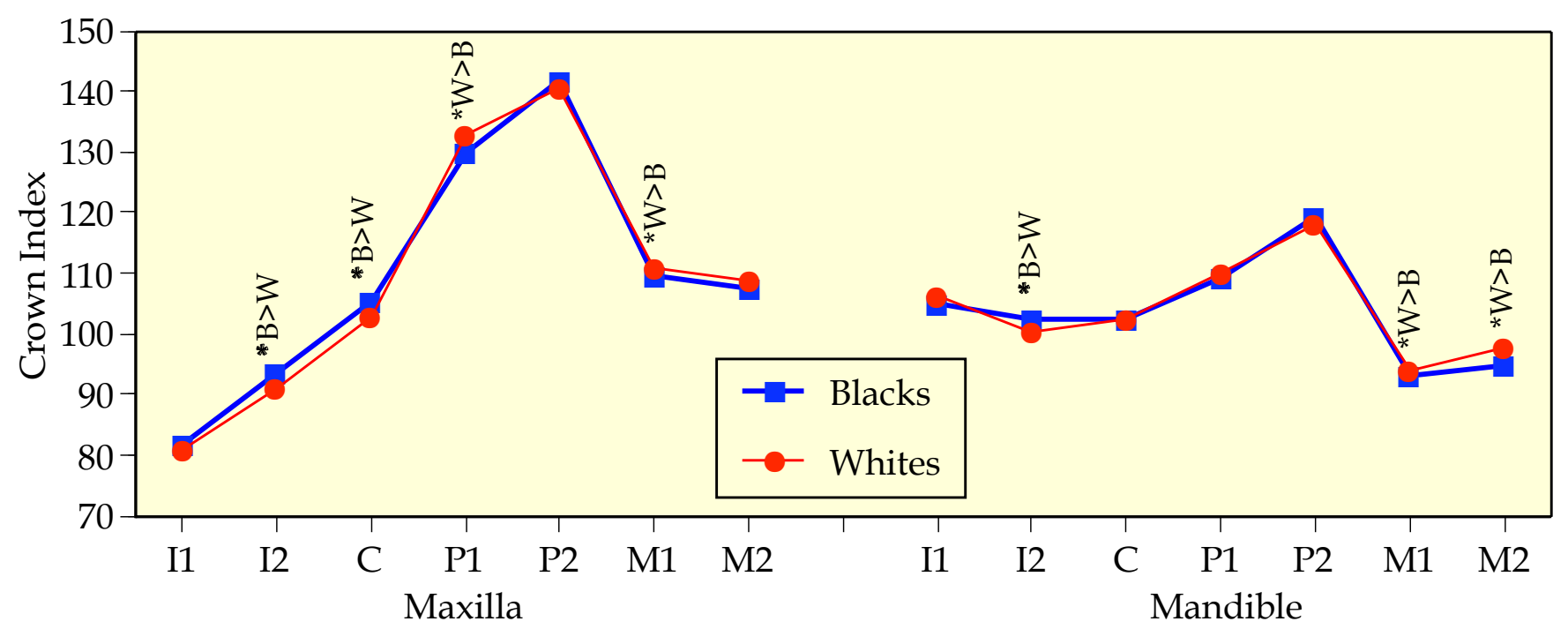

Fig 2. Plots of the mean crown index, by race and tooth type. Seven of the 14 black-white differences are significantly different as judged univariately. Blacks have larger indexes in the anterior region (incisors, canines) as denoted by the " $B>W$ " code. Indexes in the buccal segment (premolars, molars), in contrast, are larger in the white sample ("W>B"). This mixture of differences among teeth can be interpreted as region-specific changes in crown shape over the microevolutionary time separating these groups.

using these five variables. These five variables do not contribute equally to the discrimination, and the structure matrix shows that UC and LM2 are most informative. Conversely, the crown indexes for UP2 and LP2 contribute little. Retaining just the three most useful variables gives this prediction equation:

$$
\text { Race }=-11.856-0.080(\mathrm{UC})+0.079(\mathrm{UP} 1)+0.101(\mathrm{LM} 2)
$$

Correct allocation remains at $67 \%$ even with removal of the two least-informative variables. These values in the equation are the unstandardized coefficients, but their ranking is the same as when standardized: UC is the most predictive (i.e., it has the strongest correlation with the canonical function), and blacks have a higher index (relatively broader-and-shorter UC) than whites. LM2, with a higher crown index in whites, also is informative. The third variable is UP1, and it also has a higher index in whites.

Values at the group centroids are 0.270 for whites and -0.461 for blacks. Substituting actual numbers for these three crown indexes into the equation above yields a number, where a positive value suggests the specimen is a white, and a negative value suggests the specimen is a black. A value near zero is indeterminate, and the farther the value is from zero the more likely it is that the race assignment is reliable (Campbell, 1984; Kieser and Goeneveld, 1989).

The canonical function shows that UC, UP1, and LM2 exhibit the best discrimination between blacks and whites when relying on tooth crown shape. Signs of the coefficients show that separation of these two races depends on a contrast between upper canines with a short-and-broad outline (characteristic of blacks) compared to short-and-broad UP1 and LM1 (characteristic of whites). This mix of crown shapes strengthens the view that crown morphologies have diverged independently among the tooth types over time (Harris and Harris, 2007).

\section{DISCUSSION}

The crown index is an approximation of true crown shape, and it provides a comparison of shape independent of size. In turn, the number and relative sizes of cusps-the component parts of the crown-affect crown shape. The number of cusps is determined by the number of secondary enamel knots (Jernvall et al., 1994; Thesleff and Jernvall, 1997), though what controls knot formation is poorly understood. Spacing of secondary enamel knots and subsequent expansion among the cusps prior to the cessation of growth by bridging due to dentinogenesis controls cusp size and the cusps' spatial arrangement (e.g., Butler, 1967), though again little is known about the developmental mechanisms (biochemical signaling) governing these growth processes (e.g., Salazar-Ciudad, 2008; Salazar-Ciudad and Jernvall, 2002, 2004).

Physical anthropologists (as here) conventionally are limited in their analysis to the teeth themselves - the phenotypic end-products of ontogeny - so there is little to investigate about the formative processes.

\section{Sexual dimorphism}

Teeth tend to be larger in men than women, though the extent of sexual dimorphism is modest in humans compared to other species of the great apes (Swindler, 


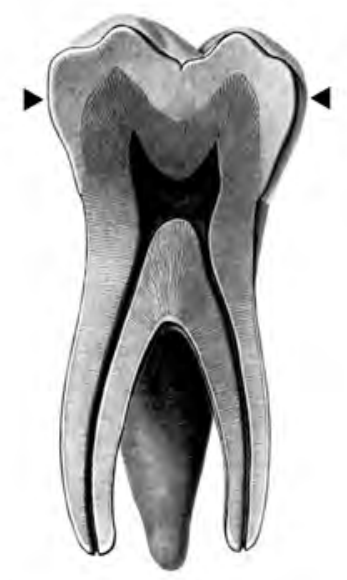

Fig. 3. Buccal view of a mandibular right $\mathrm{M} 1$ sectioned mesiodistally. The arrows mark the approximate heights of contour (defining maximum crown diameter), and it is evident that most of the "bulge" of the crown apical to the occlusal table is due to enamel thickness, but it also is contributed to by the convexity of the dentinoenamal junction that was formed by the inner enamel epithelium prior to mineralization. Diagram modified from Zeisz and Nuckolls (1949).

2002). The traditional argument is that sex hormones, notably testosterone, enhance mitotic activity to create larger teeth in males (Guatelli-Steinberg et al., 2008). Interestingly, enamel formation (amelogenesis) does not account for sex differences in tooth size (Stroud et al., 1994, 1998), though that had been a reasonable supposition (Moss, 1978). Instead, differences stem from greater dimensions of the inner enamel epithelium that are established prior to tooth mineralization (e.g., Corliss, 1976; Avery, 1994). Larger size - and any shape differences stems from growth of the inner enamel epithelium, and

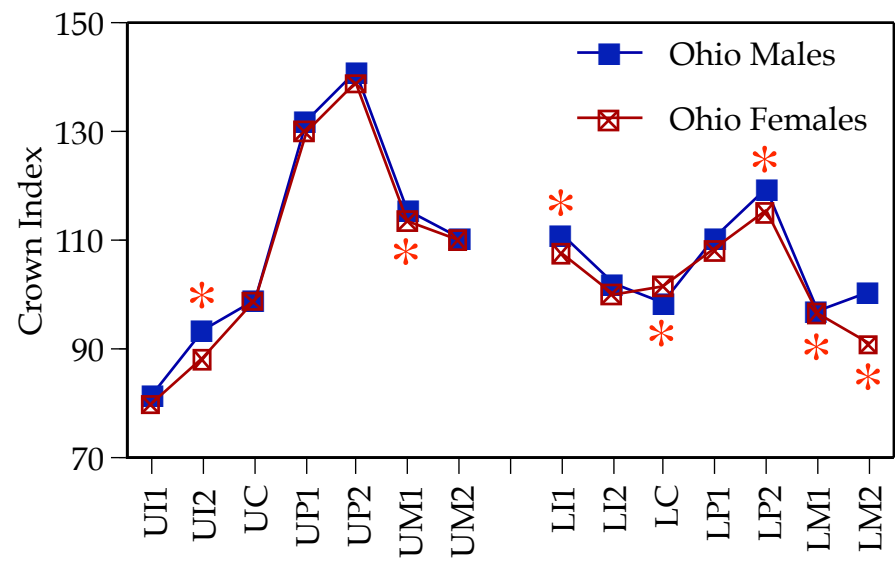

dentin formation progresses internally from this epithelial margin (Fig. 3). Greater pulp dimensions in males (Moore, 1989; Woods et al., 1990) can be viewed as the volume created by the inner enamel epithelium that is not composed of dentine in the mature tooth.

Garn et al. (1967b) suggest that a sex difference in crown indexes follows logically from the observation that percent sexual dimorphism is greater in the BL than the MD axis of teeth. This was true for his sample of whites (Garn et al., 1966) and it also is true for the present data (not shown), where percent sexual dimorphism is greater in the BL axis for 10 of the 14 tooth types. This does not, however, translate into sex differences in the crown index. Interestingly (Fig. 4), Garn's sample of whites (Yellow Springs, Ohio) possesses much greater sexual dimorphism across the crown indexes than the present sample of whites (Memphis, Tennessee). Fully half $(7 / 14)$ of the tooth types achieved a significant sex difference in Garn's sample, while, as we emphasized earlier, only the lower canine had a significant sex difference in the present study. Lack of statistical significance is not due to Type II errors insofar as our sample sizes of whites are larger than Garn's. These inter-group differences may be influenced by technical issues, such as operator bias (Kieser et al., 1990) or differences in instrumentation (Garn et al., 1967a), but we favor the issue of regional differences in tooth size among "whites" across the United States - though virtually nothing is known about this.

The present data on crown indexes show that growth of the male and female teeth are essentially isometric that males are (using this index) enlarged analogs of the female archetype. In other words, while males have metrically larger teeth (e.g., Mijsberg, 1931; Garn et al., 1964, 1967d), their length-width ratios are proportionately enlarged versions of females (Harris and Hicks, 1998), and there is the retention of the same gnomon

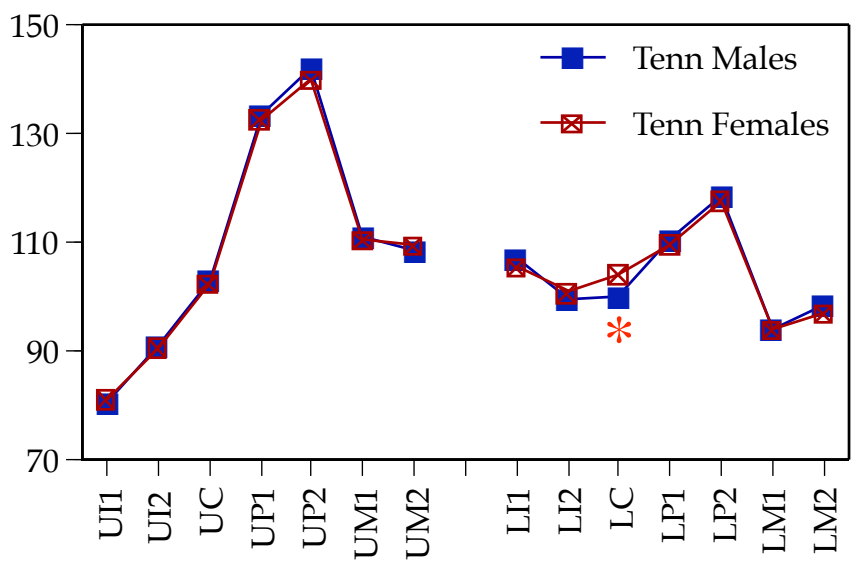

Fig. 4. Plots of the crown index for the 14 tooth types in (left) a sample of Ohio whites (Garn et al., 1967a) and (right) the present sample of whites from Tennessee. Asterisks mark the 7 tooth types that Garn et al. reported as statistically significant, whereas just one of the 14 teeth was significantly dimorphic in the present study even though sample sizes are comparable. 
(shape) with increased size (Thompson, 1948).

The one exception is the mandibular canine, where females have a distinctly higher crown index. While the $\mathrm{MD}$ and $\mathrm{BL}$ dimensions are smaller for females, their LC crowns are disproportionately shorter mesiodistally. That is, BL widths vary little between the sexes, and differences in MD lengths are about three times larger than the width difference, yielding a larger crown index in females.

\section{Black-white differences}

It has long been recognized that sub-Saharan blacks have large teeth, especially compared to rather smalltoothed Europeans (e.g., Topinard, 1886; de Terra, 1905), and more recent studies confirm this, including odontographies by Shaw (1931) and Jacobsen (1982). Likewise, early black-white comparative studies (e.g., Hrdlička, 1923; Nelson, 1938; Selmer-Olsen, 1949) show that the dental differences are complex. Differences in the crown index are location-dependent rather than uniform across the tooth types. A crude measure of this is that, of the 7 significant differences (Fig. 2), three are due to higher indexes in blacks, while the other 4 are higher in whites.

The governing principle is that blacks tend to have disproportionately broad crowns (compared to MD lengths) in the anterior segment of the arches (incisors, canines) - so crown indexes are larger than for whites. Conversely, the white sample has disproportionately broader (and/or mesiodistally shorter) crowns in the buccal segment (premolars, molars). These differences in proportionality led Harris and Rathbun (1991) to label the dentitions of sub-Saharan Africans and their derivative groups as "front loaded" in the sense that a greater portion of their overall crown size is distributed among the anterior teeth. People of European extraction, in contrast, tend towards the opposite expression, where greater portions of their overall crown area are apportioned to the premolars and molars. Of course, these proportional differences are evaluated independently of the absolute sizes of the dentitions.

This complexity of differences in crown indexes should be useful in forensic studies of estimating the race of an unknown specimen (Ditch and Rose, 1972).

\section{OVERVIEW}

Tooth crown size and shape are necessarily interrelated, and the present study assesses a time-honored approximation of crown shape, namely the crown index. Samples of American blacks and whites were analyzed from the U.S. Mid-South.

- While human males typically have larger crown dimensions, most tooth types are not sexually dimorphic in these samples. The exception is the lower canine with a significantly higher crown index in females because of disproportionately short crown lengths.

- Several tooth types exhibit significantly different crown indexes between American blacks and whites, though the indexes are a mixture of higher and lower values.

- Three variables (UC, UP1, LM2) - but especially the higher crown index of UC in blacks - are useful for discriminating between these samples of American blacks and whites.

\section{REFERENCES CITED}

Albrecht GH, Gelvin BR, Hartman SE. 1993. Ratios as a size adjustment in morphometrics. Am J Phys Anthropol 91:441-468.

Avery JK. 1994. Oral development and histology, 2nd ed. New York: Thieme Medical Publishers, Inc.

Bhaskar SN. 1962. Synopsis of oral histology. St Louis: CV Mosby Company.

Buikstra JE, Ubelaker DH, editors. 1994. Standards for data collection from human skeletal remains. Fayetteville: Arkansas Archeological Survey, Research Series, No. 44.

Butler PM. Relative growth within the human first upper permanent molar during the prenatal period. Arch Oral Biol 1967;12:983-992.

Campbell NA. 1984. Some aspects of allocation and discrimination. In: van Vark YN, Howells WW, editors. Multivariate methods in physical anthropology. Dordrecht: Reidl. p 177-192.

Cooley WW, Lohnes PR. 1971. Multivariate data analysis. New York: John Wiley \& Sons, Inc.

Corliss CE. 1976. Patton's human embryology: elements of clinical development. New York: McGraw-Hill Book Company.

Corruccini RS. Molar cusp-size variability in relation to odontogenesis in hominoid primates. Arch Oral Biol 1979;24:633-634.

Ditch LE, Rose JC. 1972. A multivariate dental sexing technique. Am J Phys Anthropol 37:61-64.

Garn SM. 1977. Genetics of tooth development. In: McNamara JA, editor. The biology of occlusal development (Craniofacial growth series). Ann Arbor, MI: Center for Human Growth and Development, University of Michigan. p 61-88.

Garn SM, Helmrich RH, Lewis AB. 1967a. Transducer caliper with readout capability for odontometry. J Dent Res 46:306.

Garn SM, Lewis AB. 1970. The gradient and the pattern of crown-size reduction in simple hypodontia. Angle Orthod 40:51-58.

Garn SM, Lewis AB, Kerewsky RS. 1964. Sex difference in tooth size. J Dent Res 43:306.

Garn SM, Lewis AB, Kerewsky RS. 1966. Sexual dimorphism in the buccolingual tooth diameter. J Dent Res 45:1819. 
Garn SM, Lewis AB, Kerewsky RS. 1967b. Sex difference in tooth shape. J Dent Res 46:1470.

Garn SM, Lewis AB, and Kerewsky RS. 1967c. Shape similarities throughout the dentition. J Dent Res 1967;46:1481.

Garn SM, Lewis AB, Swindler DR, Kerewsky RS. 1967d. Genetic control of sexual dimorphism in tooth size. J Dent Res 46:963-972.

Goose DH. 1963. Dental measurement: as assessment of its value in anthropological studies. In: Dental anthropology. Brothwell DR, editor. New York: Pergamon Press. p 125-148.

Guatelli-Steinberg D, Sciulli PW, Betsinger TK. 2008. Dental crown size and sex hormone concentrations: another look at the development of sexual dimorphism. Am J Phys Anthropol 137:324-333

Hanihara T, Ishida H. 2005. Metric dental variation of major human populations. Am J Phys Anthropol 128:287-298.

Harris EF, Harris JT. 2007. Racial differences in tooth crown size gradients within morphogenetic fields. Revista Estomatologia 15:suppl 1:7-16.

Harris EF, Hicks JD. 1998. A radiographic assessment of enamel thickness in human maxillary incisors. Arch Oral Biol 43:825-831.

Harris EF, Rathbun TA. 1991. Ethnic differences in the apportionment of tooth sizes. In: Kelley MA, Larsen CS, editors. Advances in dental anthropology. New York: Alan R. Liss, Inc. p 121-142.

Hillson S, FitzGerald C, Flinn H. 2005. Alternative dental measurements: proposals and relationships with other measurements. Am J Phys Anthropol 126:413-426.

Hrdlička A. 1923. Variation in the dimensions of lower molars in man and anthropoid apes. Am J Phys Anthropol 6:423-438.

Jacobson A. 1982. The dentition of the South African Negro. Anniston, AL: Higginbotham, Inc.

Jernvall J, Kettunen P, Karavanova I, Martin LB, Thesleff I. 1994. Evidence for the role of the enamel knot as a control center in mammalian tooth cusp formation: non-dividing cells express growth stimulating Fgf-4 gene. Int J Dev Biol 38:463-469.

Keene HJ. 1968. The relationship between Carabelli's trait and the size, number and morphology of the maxillary molars. Arch Oral Biol 13:1023-1025.

Keith A. 1916. The antiquity of man, 3rd ed. London: Williams and Norgate.

Kieser JA, Groeneveld HT.1989. Allocation and discrimination based on human odontometric data. Am J Phys Anthropol 79:331-337.

Kieser JA, Groeneveld HT, McKee J, Cameron N. 1990. Measurement error in human dental mensuration. Ann Hum Biol 17:523-528.

Kirveskari P, Hansson H, Hedegard B, Karlsson U. 1978. Crown size and hypodontia in the permanent denti- tion of modern Skolt Lapps. Am J Phys Anthropol 48:107-112.

Kondo S, Townsend GC. 2006. Associations between Carabelli trait and cusp areas in human permanent maxillary first molars. Am J Phys Anthropol 129:196203.

Korenhof CAW. 1960. Morphogenetical aspects of the human upper molar. Utrecht: Uitgeversmaatschappij Neerlandia.

Lasker GW, Lee MMC. 1957. Racial traits in the human dentition. J Forensic Sci 2:401-419.

Martin R. 1928. Lehrbuch der Anthropologie in Systematischer Darstellung. 3 vols. Jena: Gustav Fischer.

Mijsberg WA. 1931. On sexual differences in the teeth of the Javanese. Proc Akad Wettensch 34:1111-1115.

Moorrees CFA. 1957. The Aleut dentition: a correlative study of dental characteristics in an Eskimoid people. Cambridge: Harvard University Press.

Moore EE. 1989. Sexual dimorphism in enamel thickness in the human mandibular canine. Unpublished M.A. thesis, University of Tennessee, Knoxville.

Morris DH. 1965. The Anthropological Utility of Dental Morphology. Ph.D. dissertation, University of Arizona, Tucson.

Moss ML. 1978. Analysis of developmental processes possibly related to human dental sexual dimorphism. In: Butler PM, Joysey KA, editors. Development, function and evolution of teeth. London: Academic Press Inc. p 135-148.

Nelson CT. 1938. The teeth of the Indians of Pecos Pueblo. Am J Phys Anthropol 23:261-293.

Potter RH. 1972. Univariate versus multivariate differences in tooth size according to sex. J Dent Res 51:716-722.

Reyment RA, Blackith RE, Campbell NA. 1984. Multivariate morphometrics, 2nd edition. London: Academic Press.

Salazar-Ciudad I. 2008. Tooth morphogenesis in vivo, in vitro, and in silico. Curr Top Dev Biol 81:341-371.

Salazar-Ciudad I, Jernvall J. 2002. A gene network model accounting for development and evolution of mammalian teeth. PNAS 99:8116-8120.

Salazar-Ciudad I, Jernvall J. 2004. How different types of pattern formation mechanisms affect the evolution of form and development. Evol Dev 6:6-16.

Scott GR. 2008. Dental morphology. In: Katzenberg MA, Saunders SR, editors. Biological anthropology of the human skeleton, 2nd ed. New York: Wiley-Liss. $p$ 265-298.

Seipel C. 1946. Variation in tooth position: a metric study of variation and adaptation in the deciduous and permanent dentitions. Swed Dent J 39:1-176.

Selmer-Olsen R. 1949. An odontometrical study on the Norwegian Lapps. Skrifter utgitt av det Norske Videnskaps-Akademi Oslo, I. Mat-Naturv-Klasse, No. 3, p 1-167. 
Shaw JCM. 1931 The teeth the bony palate and the mandible in Bantu races of South Africa. London: John Bale, Sons, and Danielsson, Ltd.

Stroud JL, Buschang PH, Goaz PW. 1994. Sexual dimorphism in mesiodistal dentin and enamel thickness. Dentomaxillofac Radiol 23:169-171.

Stroud JL, English J, Buschang PH. 1998. Enamel thickness of the posterior dentition: its implications for nonextraction treatment. Angle Orthod 68:141-146.

Swindler DR. 2002. Primate dentition: an introduction to the teeth of non-human primates. Cambridge: Cambridge University Press.

de Terra M. 1905. Beitrage zu einer Odontographie den Menschenrassen. Berlin: Berlinishche Verlagsanstalt.

Thesleff I, Jernvall J. 1997. The enamel knot: a putative signaling center regulating tooth development. Cold Spring Harb Symp Quant Biol 62:257-267.

Thompson DW. 1942. On growth and form. Cambridge: Cambridge University Press.

Thomsen S. 1955. Dental Morphology and Occlusion in the People of Tristan da Cunha. Results of the Norwegian Scientific Expedition to Tristan da Cunha, 1937-1938, No. 25. Oslo: Det Norske Videnskpas-Akademi.

Topinard P. 1886. Les caracteres simians de la mâchoire de la Naulette. Rev d'anthroplogie de Paris 3:385431.

Turner II CG, Nichol CR, Scott GR. 1991. Scoring procedures for key morphological traits of the permanent dentition: The Arizona State University dental anthropology system. In: Kelley MA, Larsen CS, editors. Advances in dental anthropology. New York: Wiley-Liss, Inc. p 13-31.

Winer BJ, Brown DR, Michels KM. 1991. Statistical principles in experimental design, 3rd ed. New York: McGraw-Hill Book Company.

Wilder HH. 1920. A laboratory manual of anthropometry. Philadelphia: P. Blakiston's Son and Company.

Woods MA, Robinson QC, Harris EF. 1990. Age-progressive changes in pulp widths and root lengths during adulthood: a study of American blacks and whites. Gerodontology 9:41-50.

Zeisz RC, Nuckolls J. 1949. Dental anatomy. St Louis: CV Mosby Company. 